Correction

\title{
Correction: Preparation, Characterization and Evaluation of $\alpha$-Tocopherol Succinate-Modified Dextran Micelles as Potential Drug Carriers. Materials 2015, 8, 6685-6696
}

\author{
Jingmou Yu ${ }^{1, *}$, Yunfeng Zhou ${ }^{1,2}$, Wencong Chen ${ }^{1}$, Jin Ren ${ }^{1}$, Lifang Zhang ${ }^{1}$, Lu Lu ${ }^{1}$, Gan Luo $^{1}$ \\ and Hao Huang ${ }^{2, *}$
}

Received: 24 November 2015; Accepted: 24 November 2015; Published: 1 December 2015

1 School of Pharmacy and Life Sciences, Jiujiang University, 320 Xunyang East Road, Jiujiang 332000, China; zhou768417683@gmail.com (Y.Z.); chen393787420@gmail.com (W.C.); yanjiushengrj@gmail.com (J.R.); zhang524495632@gmail.com (L.Z.); yulu8275@gmail.com (L.L.); luo857084924@gmail.com (G.L.)

2 School of Chemical and Biological Engneering, Yichun University, 576 Xuefu Road, Yichun 336000, China

* Correspondence: yjm1016@jju.edu.cn (J.Y.); jxychh2008@gmail.com (H.H.); Tel./Fax: +86-792-8210-568 (J.Y.); +86-795-3201-985 (H.H.)

The authors wish to make the following correction to their paper [1]:

The second author's name "Yufeng Zhou" should be "Yunfeng Zhou".

The authors would like to apologize for any inconvenience caused to the readers by this error.

Conflicts of Interest: The authors declare no conflicts of interest.

\section{Reference}

1. Yu, J.; Zhou, Y.; Chen, W.; Ren, J.; Zhang, L.; Lu, L.; Luo, G.; Huang, H. Preparation, characterization and evaluation of $\alpha$-tocopherol succinate-modified dextran micelles as potential drug carriers. Materials 2015, 8, 6685-6696. [CrossRef]

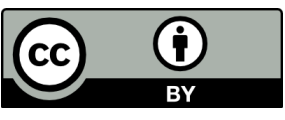

(C) 2015 by the authors; licensee MDPI, Basel, Switzerland. This article is an open access article distributed under the terms and conditions of the Creative Commons by Attribution (CC-BY) license (http://creativecommons.org/licenses/by/4.0/). 